\title{
Etiology of postoperative hyponatremia following pediatric intracranial tumor surgery
}

\author{
Cydni N. Williams, MD, ${ }^{1}$ Jay Riva-Cambrin, MD, ${ }^{2}$ and Susan L. Bratton, MD, MPH ${ }^{3}$ \\ 1Department of Pediatrics, Oregon Health and Sciences University, Portland, Oregon; and Departments of ${ }^{2}$ Neurosurgery and \\ ${ }^{3}$ Pediatrics, University of Utah, Salt Lake City, Utah
}

\begin{abstract}
OBJECTIVE Cerebral salt wasting (CSW) and the syndrome of inappropriate antidiuretic hormone secretion (SIADH) cause postoperative hyponatremia in neurosurgery patients, can be difficult to distinguish clinically, and are associated with increased morbidity. The authors aimed to determine risk factors associated with CSW and SIADH among children undergoing surgery for intracranial tumors.

METHODS This retrospective cohort study included children 0-19 years of age who underwent a first intracranial tumor surgery with postoperative hyponatremia (sodium $\leq 130 \mathrm{mEq} / \mathrm{L}$ ). CSW was differentiated from SIADH by urine output and fluid balance, exclusive of other causes of hyponatremia. The CSW and SIADH groups were compared with basic bivariate analysis and recursive partitioning.

RESULTS Of 39 hyponatremic patients, $17(44 \%)$ had CSW and $10(26 \%)$ had SIADH. Patients with CSW had significantly greater natriuresis compared with those with SIADH (median urine sodium $211 \mathrm{vs} 28 \mathrm{mEq} / \mathrm{L}, \mathrm{p}=0.01$ ). Age $\leq 7$ years and female sex were significant risk factors for CSW ( $p=0.03$ and 0.04 , respectively). Both patient groups had hyponatremia onset within the first postoperative week. Children with CSW had trends toward increased sodium variability and symptomatic hyponatremia compared with those with SIADH. Most received treatment, but inappropriate treatment was noted to worsen hyponatremia.

CONCLUSIONS The authors found that CSW was more common following intracranial tumor surgery and was associated with younger age and female sex. Careful assessment of fluid balance and urine output can separate patients with CSW from those who have SIADH, and high urine sodium concentrations (> $100 \mathrm{mEq} / \mathrm{L}$ ) support a CSW diagnosis. Patients with CSW and SIADH had similar clinical courses, but responded to different interventions, making appropriate diagnosis and treatment imperative to prevent morbidity.

http://thejns.org/doi/abs/10.3171/2015.7.PEDS15277
\end{abstract}

KEY WORDS cerebral salt wasting; syndrome of inappropriate antidiuretic hormone secretion; hyponatremia; neurosurgery; pediatrics; intracranial neoplasm; oncology

$\mathrm{H}$ YPONATREMIA occurs in approximately $12 \%$ of pediatric patients following intracranial tumor surgery. ${ }^{33,34}$ Hyponatremia from all causes among these children is associated with younger age, hydrocephalus, tumor location, malignant histological findings, and worse neurological outcomes. ${ }^{33-35}$

Postneurosurgical hyponatremia is frequently attributed to the diagnoses of cerebral salt wasting (CSW) or the syndrome of inappropriate antidiuretic hormone secretion (SIADH), but a clinical distinction between the two disorders can be challenging. $7,9,11,15,20,25,28,29,31$ CSW is generally regarded as a hypo-osmolar hyponatremic state characterized by primary natriuresis, diuresis, and subsequent volume depletion. $1,4,7,8,11,15,20,28,29,32$ SIADH is generally regarded as a hypo-osmolar hyponatremic state characterized by inappropriate free water retention, subsequent onset of natriuresis, and euvolemia. ${ }^{1,4,7,8,15,32}$ The principal defining feature distinguishing the entities is the patient's volume status, with CSW identified by high urine output and hypovolemia. . $^{1,5,-9,15,17,21,25}$ Other markers of volume status, including heart rate, central venous pressure (CVP), hemoconcentration, red blood cell or plasma volume, and

ABBREVIATIONS CSW = cerebral salt wasting; CVP = central venous pressure; $D D A V P=$ desmopressin; IQR = interquartile range; $\mathrm{RR}=$ relative risk; $\mathrm{SIADH}=$ syndrome of inappropriate antidiuretic hormone secretion.

SUBMITTED May 5, 2015. ACCEPTED July 17, 2015.

INCLUDE WHEN CITING Published online November 27, 2015; DOI: 10.3171/2015.7.PEDS15277. 
body weight changes, are inconsistently used for definitions, and some markers are infrequently available or of questionable value in clinical practice. $., 7,10,11,13,15,17,25-27,30-32$ Urine sodium concentration is the most common reported laboratory value. Both diagnoses require natriuresis with urine sodium $>20 \mathrm{mEq} / \mathrm{L} .{ }^{1,12,15,25,31}$ Some definitions require higher levels (i.e., $>100 \mathrm{mEq} / \mathrm{L}$ ) for the diagnosis of CSW. ${ }^{11,13,27}$ Appropriate diagnosis is critical given that CSW and SIADH require divergent therapies for correction of hyponatremia, and inappropriate treatment can exacerbate hyponatremia and result in patient harm. .,4,7,9,13,31 $^{-1}$

Although SIADH and CSW have been reported among a small number of pediatric patients with intracranial tumors, ${ }^{711-13}$ studies have not evaluated patient characteristics associated with CSW versus SIADH in children following neurosurgery. In this study, we aimed to determine the proportion of patients with CSW and SIADH following pediatric brain tumor surgery. We used readily available clinical measurements of urine output and fluid balance as markers of volume status, and evaluated risk factors and clinical characteristics associated with CSW and SIADH.

\section{Methods}

We conducted a single-center retrospective cohort study of children age 0-19 years who were admitted to Primary Children's Hospital between January 2001 and February 2012 following an initial brain tumor surgery. Children were identified from a database previously used to report the incidence of all causes of hyponatremia, timing and severity of hyponatremia, and neurological outcomes following brain tumor surgery. $2,34,35$ Thirty-nine $(12 \%)$ of the 319 patients in the database developed postoperative hyponatremia, ${ }^{34}$ defined as a serum sodium level $\leq 130 \mathrm{mEq} / \mathrm{L}$. An additional in-depth review of those 39 electronic and paper medical records was conducted to analyze the etiology of hyponatremia. The University of Utah's institutional review board approved the study, and granted a waiver of need for informed consent.

The etiology was categorized as CSW, SIADH, or other. The potential etiologies of hyponatremia assessed included intravenous fluid type and amount; medications (vasopressin, desmopressin [DDAVP], diuretics, mannitol, chemotherapy, antiepileptics); dilutional hyponatremia (fluid overload state, heart failure, liver failure, renal failure, anasarca); hyperosmolar hyponatremia (hyperglycemia); hypovolemic hyponatremia from vomiting or diarrhea; adrenal insufficiency; hypothyroidism; CSW; and SIADH. Prereview definitions for CSW and SIADH were consistent with previous reports in which available clinical data were used to assess volume status. . $7,11,13,25,27,32^{2}$ CSW was defined by evidence of hypovolemia (urine output $\geq 3 \mathrm{ml} / \mathrm{kg} / \mathrm{hr}$ and fluid balance $\leq 100 \mathrm{ml}$ ). SIADH was defined by evidence of euvolemia (urine output $\leq 2 \mathrm{ml} / \mathrm{kg}$ / $\mathrm{hr}$ and fluid balance $\geq 200 \mathrm{ml}$ ). The etiology was classified as "other" if patients did not meet criteria for SIADH or CSW, or if another etiology was identified on review. Patients in the "other" classification were not included in the between-group analyses. Data for urine output (in $\mathrm{ml} /$ $\mathrm{kg} / \mathrm{hr}$ ) and fluid balance (total intake minus total output in $\mathrm{ml}$ ) were calculated for up to a 12-hour period preceding the onset of hyponatremia for analysis. Most patients had hourly recordings for input and output, and all patients had recordings at least every 4 hours.

Other potential markers of volume status, including CVP and heart rate standardized to age, ${ }^{18}$ were assessed when available. Urine sodium concentrations were collected when available. Urine sodium measurements $>20$ $100 \mathrm{mEq} / \mathrm{L}$ were considered consistent with SIADH and measurements $>100 \mathrm{mEq} / \mathrm{L}$ were considered consistent with CSW. ${ }^{11,13,27}$ No patient had measured values inconsistent with the initial assigned diagnosis.

Tumor locations, metastases, histological findings, hydrocephalus, and stroke were collected from radiological, surgical, and pathology reports. ${ }^{34}$ Infection included pneumonia, bacteremia, meningitis, and urinary tract infections. Sodium variability and severity of hyponatremia were obtained from laboratory data consistent with our previous report. ${ }^{2}$ One patient with SIADH had pre- and postoperative hyponatremia, and only the postoperative course was analyzed in that individual.

Times of low sodium values were used to review for the presence of hyponatremia symptoms, including altered mental status and seizures. ${ }^{34}$ The sodium level at the time of the symptom and any treatments received were also recorded. Treatment of hyponatremia included normal saline fluid bolus, hypertonic saline infusion, enteral sodium chloride supplementation, a change to the maintenance intravenous fluid rate or type of fluid, and fluid intake restriction. The response to treatment, evaluated by changes in serum sodium, was noted.

Data were analyzed with the $\mathrm{R}$ statistical analysis program (version 2.15.2, www.R-project.com). Univariate results were expressed as counts with percentages for categorical variables, and as medians with the interquartile range (IQR) for continuous variables. Bivariate analyses for differences between the CSW and SIADH groups were conducted using Fisher exact (categorical variables) and Kruskal-Wallis (continuous variables) methods. Relative risk (RR) with a 95\% CI was calculated when applicable. All tests were 2-tailed. Significance was defined as $p<0.05$. Recursive partitioning was used to create a risk-stratified flow diagram for risk of CSW between the 2 study groups by using significant variables from the bivariate analyses.

\section{Results}

Thirty-nine patients had postneurosurgical hyponatremia-17 (44\%) had CSW, 10 (26\%) had SIADH, and 12 (31\%) had other etiologies identified (Table 1). All patients received postoperative dexamethasone, and they received intravenous fluid at maintenance rates until they tolerated enteral diets. The intravenous fluid type varied during the study period $(p=0.009)$. The rate of hyponatremia did not vary with study year or intravenous fluid type. ${ }^{34}$ The etiology of hyponatremia did not vary by year $(p=0.9)$. Sodium content and rate of fluid varied at the onset of hyponatremia but were similar between groups; more than half of patients $(n=9$ with CSW, $n=6$ with SIADH) were receiving maintenance intravenous $0.9 \%$ saline, and the 
TABLE 1. Etiologies other than CSW or SIADH for postoperative hyponatremia in 12 patients

\begin{tabular}{lc}
\hline \multicolumn{1}{c}{ Other Etiology } & $\begin{array}{c}\text { No. of } \\
\text { Patients }\end{array}$ \\
\hline $\begin{array}{l}\text { Vasopressin or DDAVP administration } \\
\quad \text { tion }\end{array}$ & 5 \\
\hline $\begin{array}{l}\text { Severe vomiting \& dehydration } \\
\text { Fluid overload following aspiration-induced ARDS }\end{array}$ & 3 \\
\hline Indeterminate/multiple possible etiologies & 1 \\
\hline
\end{tabular}

ARDS = acute respiratory distress syndrome.

rest ( $\mathrm{n}=8$ with CSW, $\mathrm{n}=4$ with SIADH) were receiving intravenous $0.45 \%$ saline, enteral feeding only, or a combination of intravenous fluids and feeding methods. Fewer patients were receiving $0.9 \%$ saline at the onset of hyponatremia as time from the surgical procedure increased ( $\mathrm{p}$ $=0.007$ ). No patients with CSW or SIADH were receiving diuretics prior to hyponatremia onset.

Demographic and clinical characteristics for the patients with CSW and SIADH are presented in Table 2. Patients with CSW were significantly younger $(p=0.02)$, and a higher proportion was female (RR 1.9, 95\% CI 1.1-3.3). The median age was 1.6 years for patients with CSW and 8.1 years for those with SIADH, with age $<4.3$ years in $75 \%$ of patients with CSW. Recursive partitioning revealed age $\leq 7$ years as the most significant risk factor for CSW, and female sex portended an even greater risk among young patients (Fig. 1).

Urine sodium measurements were obtained in approximately half of patients at the onset of hyponatremia. When measured, all patients classified as CSW $(n=11)$ had urine sodium measurements $>140 \mathrm{mEq} / \mathrm{L}$ and all patients classified as SIADH $(\mathrm{n}=3)$ had urine sodium measurements $>25$ and $<70 \mathrm{mEq} / \mathrm{L}$. Most patients underwent resection for their intracranial tumor, but 1 patient with CSW underwent biopsy only prior to hyponatremia. Tumor characteristics did not vary by group. Obstructive hydrocephalus and related ventriculostomy or shunt placement were common and similar between groups. No patients had an infection diagnosed prior to hyponatremia onset.

Markers of hyponatremia severity and sodium variability for patients with CSW and SIADH are presented in Table 3. Rapid serum sodium drops of $>10 \mathrm{mEq} / \mathrm{L}$ within any 24-hour period occurred in a higher but nonsignificant proportion (41\% vs $10 \%$ ) of patients with CSW (RR

TABLE 2. Demographic and clinical characteristics by etiology of hyponatremia

\begin{tabular}{|c|c|c|c|}
\hline Characteristic & CSW & SIADH & p Value \\
\hline No. of patients & 17 & 10 & \\
\hline Median age in yrs (IQR) & $1.6(1.4-4.3)$ & $8.1(2.8-11)$ & 0.02 \\
\hline Female sex & $9(53 \%)$ & $1(10 \%)$ & 0.04 \\
\hline Race/ethnicity & & & 0.33 \\
\hline Caucasian & $15(88 \%)$ & $7(70 \%)$ & \\
\hline Other & $2(12 \%)$ & $3(30 \%)$ & \\
\hline Median fluid balance in ml (IQR) & $-156(-326$ to 3$)$ & $348(298-444)$ & * \\
\hline Median urine output in ml/kg/hr (IQR) & $3.9(3.5-5.1)$ & $1.4(1.1-1.6)$ & * \\
\hline Median CVP in mm Hg (IQR)† & $2(1-3)$ & $6(3-9)$ & 0.06 \\
\hline Heart rate for age $\ddagger$ & & & $>0.99$ \\
\hline Tachycardia & $3(18 \%)$ & $1(10 \%)$ & \\
\hline Bradycardia & $1(6 \%)$ & 0 & \\
\hline Normal & $13(76 \%)$ & $9(90 \%)$ & \\
\hline Median urine sodium in $\mathrm{mEq} / \mathrm{L}(\mathrm{IQR}) \S$ & $211(186-254)$ & $28(27-45)$ & 0.01 \\
\hline Tumor location & & & 0.80 \\
\hline Cortex & $1(6 \%)$ & $2(20 \%)$ & \\
\hline Cerebellum or brainstem & $5(29 \%)$ & $2(20 \%)$ & \\
\hline Deep brain or ventricles & $6(35 \%)$ & $3(30 \%)$ & \\
\hline Overlapping & $5(29 \%)$ & $3(30 \%)$ & \\
\hline Malignant histological findings & $11(65 \%)$ & $8(80 \%)$ & 0.67 \\
\hline Metastases & $4(24 \%)$ & $2(20 \%)$ & $>0.99$ \\
\hline Obstructive hydrocephalus & $14(82 \%)$ & $7(70 \%)$ & 0.64 \\
\hline Ventriculostomy & $13(76 \%)$ & $7(70 \%)$ & $>0.99$ \\
\hline Ventriculoperitoneal shunt & $4(24 \%)$ & $3(30 \%)$ & $>0.99$ \\
\hline Postop stroke & $2(12 \%)$ & 0 & 0.52 \\
\hline
\end{tabular}




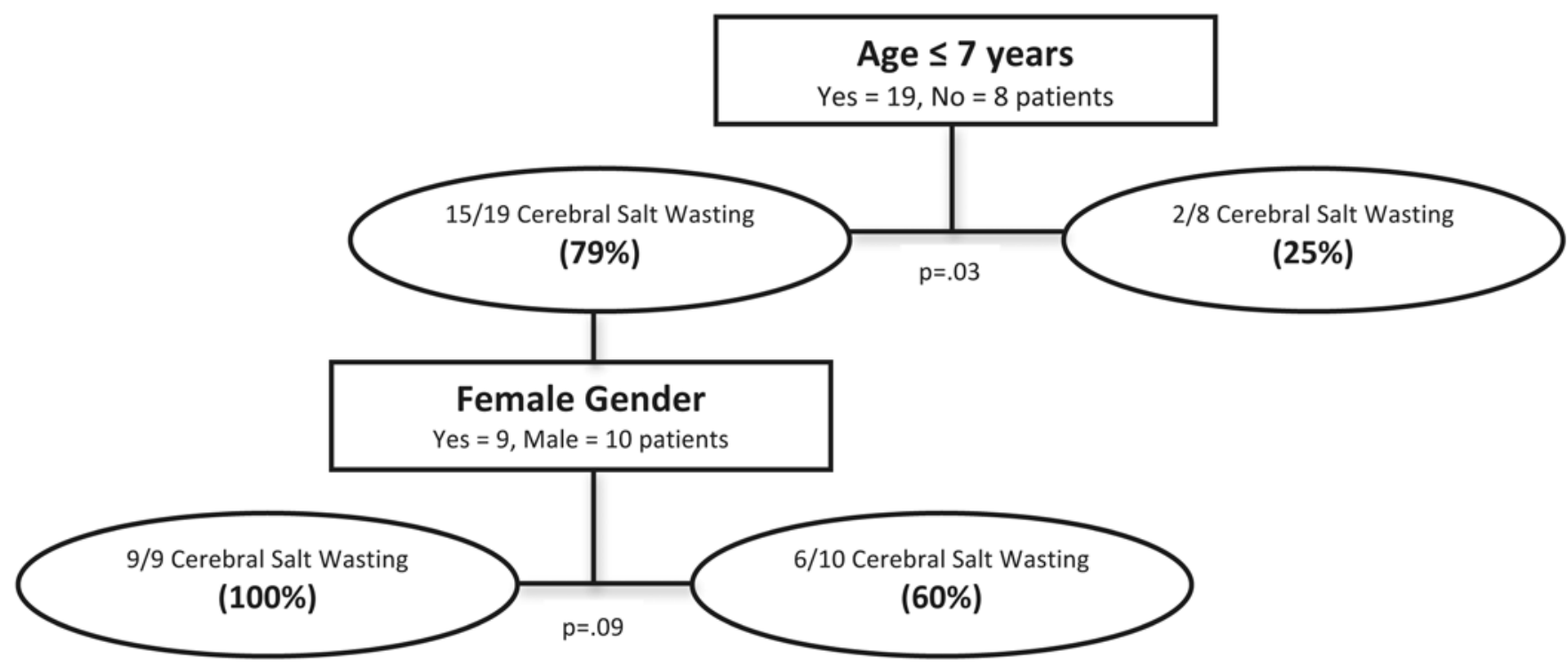

FIG. 1. Multivariable modeling with recursive partitioning revealed that patient age $\leq 7$ years was the most important risk factor for CSW. Following age, female sex portended greater risk of CSW versus SIADH.

1.7, 95\% CI 1.0-2.7). There was a nonsignificant trend toward lower sodium nadir and higher maximum sodium among patients with CSW compared with SIADH. Serum sodium values $\leq 135 \mathrm{mEq} / \mathrm{L}$ manifested in all patients within 6 postoperative days, and onset was within 2 postoperative days for $75 \%$ of patients in both groups. Time to first serum sodium value $\leq 130 \mathrm{mEq} / \mathrm{L}$ was more variable, occurring within 5 postoperative days for $75 \%$ of patients, but up to 13 days for the CSW group and up to 21 days for the SIADH group.

Symptomatic hyponatremia with altered mental status or hyponatremic seizures occurred in a nonsignificant but higher proportion of patients with CSW versus SIADH (47\% vs 20\%; RR 1.5, 95\% CI 0.9-2.6). Hyponatremic seizures occurred in $5(29 \%)$ patients with CSW and no patients with SIADH (RR 1.8, 95\% CI 1.3-2.7). The median serum sodium level for all patients with altered mental status was 126 mEq/L (IQR 123, 129; Range 120-130) and with hyponatremic seizures it was $123 \mathrm{mEq} / \mathrm{L}$ (IQR 120, 127; Range 110-130), and this did not vary by group $(p=0.89)$. All patients with hyponatremic seizures were treated with hypertonic saline infusion. Seventy-five percent of patients with altered mental status were treated with hypertonic saline, whereas others received normal saline boluses or enteral salt supplementation at the time of the symptom.

Nine $(90 \%)$ patients in the SIADH group were treated with fluid restriction, enteral sodium supplementation, and/or hypertonic saline. One (10\%) patient with SIADH did not receive treatment, had a sodium nadir of 130 $\mathrm{mEq} / \mathrm{L}$, and was asymptomatic. All patients with CSW were eventually treated with increased fluid and sodium supplementation; however, 4 (24\%) patients with CSW were treated with fluid restriction prior to receiving appropriate therapy. Three of these 4 patients had no symptoms or significant worsening of hyponatremia prior to recognition and a change to appropriate management. One of these 4 patients with CSW had a sodium decrease from 131 to $124 \mathrm{mEq} / \mathrm{L}$ after institution of fluid restriction, and experienced altered mental status prior to being treated

TABLE 3. Sodium measurements by etiology of hyponatremia

\begin{tabular}{lccc}
\hline \multicolumn{1}{c}{ Sodium Measurement } & CSW & SIADH & p Value \\
\hline No. of patients & 17 & 10 & 0.19 \\
\hline Decrease $>10 \mathrm{mEq} / \mathrm{L}$ in $24 \mathrm{hrs}$ & $7(41 \%)$ & $1(10 \%)$ & 0.25 \\
\hline Median value $(\mathrm{IQR})$ & & & $134.7(133-136.6)$ \\
\hline Average sodium, in $\mathrm{mEq} / \mathrm{L}$ & $135.9(134.3-136.8)$ & $130(127.5-130)$ & 0.24 \\
\hline Nadir sodium, in $\mathrm{mEq} / \mathrm{L}$ & $127(124-130)$ & $141.5(139.3-143.8)$ & 0.14 \\
\hline Maximum sodium, in $\mathrm{mEq} / \mathrm{L}$ & $144(141-148)$ & $1.26(0.28-4.28)$ & 0.62 \\
\hline Onset of sodium $\leq 130 \mathrm{mEq} / \mathrm{L}$, in days & $1.7(0.99-2.65)$ & $0.17(0.06-0.65)$ & 0.05 \\
\hline Onset of sodium $\leq 135 \mathrm{mEq} / \mathrm{L}$, in days & $0.83(0.38-1.43)$ & $0.49(0.19-1.14)$ & 0.48 \\
\hline Duration of sodium $\leq 130 \mathrm{mEq} / \mathrm{L}$, in days & $0.65(0.32-1.26)$ & $9.08(5.5-18.9)$ & 0.80 \\
\hline Duration of sodium $\leq 135 \mathrm{mEq} / \mathrm{L}$, in days & $7.56(4.45-19.97)$ & $1.5(1-4.25)$ & 0.62 \\
\hline Episodes of sodium $\leq 130 \mathrm{mEq} / \mathrm{L}$ & $2(1-5)$ & $2(2-8)$ & 0.27 \\
\hline Episodes of sodium $\leq 135 \mathrm{mEq} / \mathrm{L}$ & $6(2-11)$ & & \\
\hline
\end{tabular}


with hypertonic saline and increased maintenance fluids, which corrected the hyponatremia.

\section{Discussion}

We classified hyponatremia etiology by excluding other known causes and using the commonly available measures of urine output and fluid balance as surrogates for the patient's volume status, consistent with previous reports. ${ }^{4,7,11,13,25,27,32}$ No universal diagnostic criteria exist to distinguish SIADH and CSW despite a recent systematic review ${ }^{20}$ and published European guidelines on hyponatremia, ${ }^{28}$ although differences in volume status are reinforced. Invasive measures of volume status are often not available and are impractical when managing hyponatremia in the acute setting. Given these limitations, clinicians are faced with determining volume status by clinical judgment and available surrogates, like urine volume and fluid balance, which are the variables we chose to define groups. Urine volume and fluid balance often vary in the postoperative period, so we chose to calculate totals for the 12 hours preceding hyponatremia documentation in hopes of capturing only the most recent patient trends. Our classifications were supported by urine sodium measurements when available, because patients with CSW had significantly greater natriuresis (urine sodium $>100$ $\mathrm{mEq} / \mathrm{L}$ ), consistent with previous reports. ${ }^{11,13,27,32}$ Additionally, our proportion of patients with CSW is consistent with a smaller postoperative study of pediatric patients treated for brain tumor, which reported that $50 \%$ of hyponatremic patients had CSW. ${ }^{11}$ Our patients also showed improvement with appropriate therapy.

Other clinical markers of volume status (heart rate and CVP) did not differ between groups and were not useful to estimate volume status, similar to findings in other reports. ${ }^{7,13,32}$ Heart rate is a nonspecific marker of volume status in neurosurgical patients, given the commonly encountered confounders of pain, sedative medications, anemia, and so on in the postoperative period. The CVP has been used as the sole determinant of volume status and hyponatremia etiology; ${ }^{10,17}$ however, this marker has been questioned as a surrogate for volume status $s^{4,15,16}$ and is infrequently available postoperatively among pediatric patients who have been treated for brain tumors. ${ }^{11}$ Among our patients, trends toward lower CVP with CSW compared with SIADH were seen, but few had measurements available. Historically, central venous catheters were placed for intraoperative monitoring and vascular access, but are now infrequent, and when placed are often removed in the immediate postoperative period.

Age $\leq 7$ years and female sex were important risk factors for CSW compared with SIADH. We previously reported a significant association between all causes of hyponatremia and young age. ${ }^{2,34}$ Hardesty et al. also noted an association between young age and CSW in hyponatremic patients compared with eunatremic patients. ${ }^{11}$ The association between age and CSW may reflect the relative immaturity of renal and brain tissues in young patients. One hypothesis for the cause of CSW is disruption of sympathetic signaling to the kidney, ${ }^{5,8,9,21,31}$ so young patients with immature sympathetic nervous systems may be at in- creased risk of the disorder. A study of adult neurosurgical patients, including a proportion with tumors, found that SIADH was more common compared with CSW (62\% vs $5 \%){ }^{25}$ Sex hormones have been associated with antidiuretic hormone release, ${ }^{21}$ which may account for some increased risk of SIADH in older pubertal children and adults. Overall hyponatremia risk does not vary by sex in adults, but premenopausal females have been reported to be more likely to suffer morbidity from hyponatremic encephalopathy thought to be a result of hormonal differences. ${ }^{19,21}$ Additionally, the vasopressin receptor V2 is encoded on the $\mathrm{X}$ chromosome and transcription may occur in higher levels in females,${ }^{14}$ which may predispose to sex differences.

We did not find differences in tumor locations between CSW and SIADH groups, although numbers of tumors in each region were low. Prior studies reported an association between CSW and chiasmatic/hypothalamic tumors when patients with CSW were compared to eunatremic patients ${ }^{11}$ and an association between SIADH and cortical tumors when patients with SIADH were compared to patients with diabetes insipidus. ${ }^{12}$ No prior studies have compared tumor locations between patients with SIADH and CSW. The pathogenesis of SIADH relates to loss of normal feedback mechanisms and release of antidiuretic hormone from the supraoptic and paraventricular nuclei of the hypothalamus, ${ }^{9,21,31}$ so tumors or surgeries in this area may contribute to the development of this syndrome. ${ }^{31,33}$ However, SIADH can result from location-independent variables, including stress, pain, and nausea, ${ }^{9,19}$ and elevated levels of ADH are found in patients with CSW due to hypovolemia. $6,21,30,31$ Additionally, natriuretic peptides released by the hypothalamus may contribute to the development of CSW. ${ }^{7-9}$ However, the distribution of natriuretic peptides is not uniform in the brain, ${ }^{3}$ their elevation in CSW is not consistent, ${ }^{8,9,26}$ and they can be elevated in patients with SIADH. ${ }^{24,30}$ Until we understand the exact pathogenesis of CSW and SIADH, an association with tumor or surgical location may not be found.

Both groups had sodium levels $\leq 135 \mathrm{mEq} / \mathrm{L}$, and most had sodium levels $\leq 130 \mathrm{mEq} / \mathrm{L}$ within the first postoperative week. Our data are consistent with studies showing a similar onset within the first week after any neurological insult for patients with CSW or SIADH. ${ }^{4,7,11-13,17,23,25,27,32}$ Most patients had a limited duration of hyponatremia, which is consistent with previous reports that SIADH and CSW are usually self-limited; $711-13,17,25,32$ however, some patients with CSW and SIADH had prolonged courses lasting for weeks. ${ }^{7,11,13,22,32}$ Larger studies could assess patient or disease characteristics that could account for later onset and prolonged disease.

We noted a trend toward increased sodium variability in patients with CSW compared to those with SIADH, and we are unaware of other studies assessing sodium variability between these diagnoses. It is unclear if sodium variability reflects pathophysiological mechanisms or response to treatment. We also noted a trend toward increased symptomatic hyponatremia among patients with CSW. Hardesty et al. noted a high incidence of seizures among pediatric patients with brain tumors who had CSW.1 ${ }^{11}$ The concern with hyponatremia is the develop- 
ment of neurological complications from cerebral edema, ${ }^{5,19,21}$ which is more likely to occur with acute decreases in serum sodium,, 921 and is less well tolerated among pediatric patients and those with neurological disease. . $9,21,24,31^{2}$

The need for proper identification and treatment of SI$\mathrm{ADH}$ and CSW to prevent patient harm is well documented. ${ }^{1,4,7,9,13,31}$ Most of our patients received appropriate therapies; however, 1 patient had worsening hyponatremia and encephalopathy after apparently improper management. This patient had urine output $>3 \mathrm{ml} / \mathrm{kg} / \mathrm{hr}$, negative fluid balance, and urine sodium $>200 \mathrm{mEq} / \mathrm{L}$. Careful review of these available data may have been able to prevent the subsequent worsening of hyponatremia after fluid restriction if the diagnosis of CSW had been made initially. This case and others ${ }^{7}$ reported as receiving improper treatment highlight the difficulty sometimes present in distinguishing these conditions. Despite the variability that exists in defining the diagnosis of CSW, there appear to be readily available clinical tools (urine output and fluid balance) to help steer clinicians toward proper diagnosis and to prompt further investigation, such as urine sodium, when the diagnosis is unclear.

Our study has several limitations to consider. The retrospective nature of data collection cannot ensure the accuracy of all collected variables. Even though this is the largest cohort of hyponatremic pediatric patients with brain tumors in which etiology was evaluated, our sample was inadequately powered to detect differences in some clinical characteristics, so caution is needed when interpreting data trends. Care practices at our institution have evolved over the study period, particularly with regard to sodium content of intravenous fluids, and the effect of changing practices could not be assessed with the small sample size. Additionally, because a universally accepted definition for the diagnosis of CSW does not exist, the accuracy of our classifications cannot be ensured, although they were supported by review of urine sodium measurements and response to treatments, consistent with previously reported definitions, and our results were similar to those reported in the literature for other neurosurgical patients. Future research assessing differences between the characteristics of patients with CSW and those with SIADH should include a larger cohort of patients, consideration of prospective data collection with inclusion of additional markers of volume status, and standardized diagnostic and treatment protocols to limit confounding variables.

\section{Conclusions}

Our previous works have shown that hyponatremia after pediatric brain tumor surgery is common, particularly among young children with hydrocephalus, and is associated with worsened cognitive outcome. ${ }^{2,33-35} \mathrm{CSW}$ was the most common cause of hyponatremia among our cohort and, compared with SIADH, was significantly associated with young age and female sex. Both conditions manifest within the first postoperative week. The commonly available clinical measurements of fluid balance and urine volume can establish a diagnosis of CSW or SIADH in most cases. Urine sodium measurements may provide an additional distinction, because patients with CSW exhibited a significantly greater natriuresis at the onset of hyponatremia $(\mathrm{CSW}>140 \mathrm{mEq} / \mathrm{L}$ vs $\mathrm{SIADH}>25-70 \mathrm{mEq} / \mathrm{L})$. Given this information, we recommend the routine use of $0.9 \%$ saline when intravenous fluid supplementation is required and that serum sodium be closely monitored for at least several days after surgery, especially in young children with hydrocephalus. When hyponatremia occurs, we recommend evaluation of the patient's volume status, with fluid balance and urine volume, and urine sodium measurements to distinguish CSW from SIADH and to help guide therapy.

\section{Acknowledgments}

This work was performed while Dr. Williams was employed at the University of Utah, Primary Children's Hospital, Salt Lake City, Utah.

\section{References}

1. Albanese A, Hindmarsh P, Stanhope R: Management of hyponatraemia in patients with acute cerebral insults. Arch Dis Child 85:246-251, 2001

2. Belzer JS, Williams CN, Riva-Cambrin J, Presson AP, Bratton SL: Timing, duration, and severity of hyponatremia following pediatric brain tumor surgery. Pediatr Crit Care Med 15:456-463, 2014

3. Berger TM, Kistler W, Berendes E, Raufhake C, Walter M: Hyponatremia in a pediatric stroke patient: syndrome of inappropriate antidiuretic hormone secretion or cerebral salt wasting? Crit Care Med 30:792-795, 2002

4. Berkenbosch JW, Lentz CW, Jimenez DF, Tobias JD: Cerebral salt wasting syndrome following brain injury in three pediatric patients: suggestions for rapid diagnosis and therapy. Pediatr Neurosurg 36:75-79, 2002

5. Bettinelli A, Longoni L, Tammaro F, Faré PB, Garzoni L, Bianchetti MG: Renal salt-wasting syndrome in children with intracranial disorders. Pediatr Nephrol 27:733-739, 2012

6. Brimioulle S, Orellana-Jimenez C, Aminian A, Vincent JL: Hyponatremia in neurological patients: cerebral salt wasting versus inappropriate antidiuretic hormone secretion. Intensive Care Med 34:125-131, 2008

7. Bussmann C, Bast T, Rating D: Hyponatraemia in children with acute CNS disease: SIADH or cerebral salt wasting? Childs Nerv Syst 17:58-63, 2001

8. Cerdà-Esteve M, Cuadrado-Godia E, Chillaron JJ, Pont-Sunyer C, Cucurella G, Fernández M, et al: Cerebral salt wasting syndrome: review. Eur J Intern Med 19:249-254, 2008

9. Cole CD, Gottfried ON, Liu JK, Couldwell WT: Hyponatremia in the neurosurgical patient: diagnosis and management. Neurosurg Focus 16(4):E9, 2004

10. Damaraju SC, Rajshekhar V, Chandy MJ: Validation study of a central venous pressure-based protocol for the management of neurosurgical patients with hyponatremia and natriuresis. Neurosurgery 40:312-317, 1997

11. Hardesty DA, Kilbaugh TJ, Storm PB: Cerebral salt wasting syndrome in post-operative pediatric brain tumor patients. Neurocrit Care 17:382-387, 2012

12. Hiranrat P, Katavetin P, Supornsilchai V, Wacharasindhu S, Srivuthana S: Water and sodium disorders in children undergoing surgical treatment of brain tumors. J Med Assoc Thai 86 (Suppl 2):S152-S159, 2003

13. Jiménez R, Casado-Flores J, Nieto M, García-Teresa MA: Cerebral salt wasting syndrome in children with acute central nervous system injury. Pediatr Neurol 35:261-263, 2006

14. Juul KV, Bichet DG, Nielsen S, Nørgaard JP: The physiological and pathophysiological functions of renal and extrarenal 
vasopressin V2 receptors. Am J Physiol Renal Physiol 306:F931-F940, 2014

15. Kirkman MA, Albert AF, Ibrahim A, Doberenz D: Hyponatremia and brain injury: historical and contemporary perspectives. Neurocrit Care 18:406-416, 2013

16. Kumar A, Anel R, Bunnell E, Habet K, Zanotti S, Marshall $\mathrm{S}$, et al: Pulmonary artery occlusion pressure and central venous pressure fail to predict ventricular filling volume, cardiac performance, or the response to volume infusion in normal subjects. Crit Care Med 32:691-699, 2004

17. Lohani S, Devkota UP: Hyponatremia in patients with traumatic brain injury: etiology, incidence, and severity correlation. World Neurosurg 76:355-360, 2011

18. Marx J, Hockberger R, Walls R: Rosen's Emergency Medicine-Concepts and Clinical Practice, ed 8. Philadelphia: Saunders, 2013

19. Moritz ML, Ayus JC: New aspects in the pathogenesis, prevention, and treatment of hyponatremic encephalopathy in children. Pediatr Nephrol 25:1225-1238, 2010

20. Nagler EV, Vanmassenhove J, van der Veer SN, Nistor I, Van Biesen W, Webster AC, et al: Diagnosis and treatment of hyponatremia: a systematic review of clinical practice guidelines and consensus statements. BMC Med 12:1, 2014

21. Nathan BR: Cerebral correlates of hyponatremia. Neurocrit Care 6:72-78, 2007

22. Oruckaptan HH, Ozisik P, Akalan N: Prolonged cerebral salt wasting syndrome associated with the intraventricular dissemination of brain tumors. Report of two cases and review of the literature. Pediatr Neurosurg 33:16-20, 2000

23. Papadimitriou DT, Spiteri A, Pagnier A, Bayle M, Mischalowski MB, Bourdat G, et al: Mineralocorticoid deficiency in post-operative cerebral salt wasting. J Pediatr Endocrinol Metab 20:1145-1150, 2007

24. Rivkees SA: Differentiating appropriate antidiuretic hormone secretion, inappropriate antidiuretic hormone secretion and cerebral salt wasting: the common, uncommon, and misnamed. Curr Opin Pediatr 20:448-452, 2008

25. Sherlock M, O'Sullivan E, Agha A, Behan LA, Owens D, Finucane F, et al: Incidence and pathophysiology of severe hyponatraemia in neurosurgical patients. Postgrad Med J 85:171-175, 2009

26. Singh S, Bohn D, Carlotti AP, Cusimano M, Rutka JT, Halperin ML: Cerebral salt wasting: truths, fallacies, theories, and challenges. Crit Care Med 30:2575-2579, 2002

27. Sorkhi H, Salehi Omran MR, Barari Savadkoohi R, Baghdadi F, Nakhjavani N, Bijani A: CSWS versus SIADH as the probable causes of hyponatremia in children with acute CNS disorders. Iran J Child Neurol 7:34-39, 2013
28. Spasovski G, Vanholder R, Allolio B, Annane D, Ball S, Bichet D, et al: Clinical practice guideline on diagnosis and treatment of hyponatraemia. Intensive Care Med 40:320331, 2014 (Erratum in Intensive Care Med 40:924, 2014)

29. Sterns RH: Disorders of plasma sodium-causes, consequences, and correction. N Engl J Med 372:55-65, 2015

30. Sterns RH, Silver SM: Cerebral salt wasting versus SIADH: what difference? J Am Soc Nephrol 19:194-196, 2008

31. Upadhyay UM, Gormley WB: Etiology and management of hyponatremia in neurosurgical patients. J Intensive Care Med 27:139-144, 2012

32. von Bismarck P, Ankermann T, Eggert P, Claviez A, Fritsch MJ, Krause MF: Diagnosis and management of cerebral salt wasting (CSW) in children: the role of atrial natriuretic peptide (ANP) and brain natriuretic peptide (BNP). Childs Nerv Syst 22:1275-1281, 2006

33. Williams C, Simon TD, Riva-Cambrin J, Bratton SL: Hyponatremia with intracranial malignant tumor resection in children. J Neurosurg Pediatr 9:524-529, 2012

34. Williams CN, Belzer JS, Riva-Cambrin J, Presson AP, Bratton SL: The incidence of postoperative hyponatremia and associated neurological sequelae in children with intracranial neoplasms. J Neurosurg Pediatr 13:283-290, 2014

35. Williams CN, Riva-Cambrin J, Presson AP, Bratton SL: Hyponatremia and poor cognitive outcome following pediatric brain tumor surgery. J Neurosurg Pediatr 15:480-487, 2015

\section{Disclosures}

The authors report no conflict of interest concerning the materials or methods used in this study or the findings specified in this paper.

\section{Author Contributions}

Conception and design: Williams. Acquisition of data: Williams. Analysis and interpretation of data: all authors. Drafting the article: Williams. Critically revising the article: Riva-Cambrin, Bratton. Reviewed submitted version of manuscript: all authors. Approved the final version of the manuscript on behalf of all authors: Williams. Statistical analysis: Williams, Bratton. Administrative/technical/material support: Riva-Cambrin. Study supervision: Bratton.

\section{Correspondence}

Cydni N. Williams, Pediatric Critical Care, 707 SW Gaines St., CDRC-P, Portland, OR 97239. email: willicyd@ohsu.edu. 